\title{
Implementing general practice in Russia: getting beyond the first steps
}

\author{
Andrey Rese, Dina Balabanova, Kirill Danishevski, Martin McKee, Rod Sheaff \\ Russia has been trying to establish a model of primary health care based on integrated general \\ practice. Is it managing to shake off the old attitudes and infrastructures of the Soviet era?
}

\section{All-Russia \\ Association of \\ General \\ Practitioners, \\ Rossolimo str 11a, \\ Moscow 119881, \\ Russian Federation \\ Andrey Rese \\ member of executive \\ board \\ Health Systems \\ Developmen \\ Programme, \\ London School of \\ Hygiene and \\ Tropical Medicine, \\ London \\ WC1E 7HT \\ Dina Balabanova \\ lecturer \\ Moscow Medical \\ Academy, Ferganski \\ Prospect 14-3-55, \\ Moscow 109507. \\ Russian Federation \\ Kirill Danishevski \\ lecturer \\ European Centre \\ on Health of \\ Societies in \\ Transition, London \\ School of Hygiene \\ and Tropical \\ Medicine \\ Martin McKee \\ professor of European \\ public health \\ National Primary \\ Care Resource and \\ Development \\ Centre, Manchester \\ University, \\ Manchester \\ M13 9PL \\ Rod Sheaff \\ senior research fellow \\ Correspondence to: \\ D Balabanova \\ dina.balabanova@ \\ lshtm.ac.uk}

BMJ 2005;331:204-7
Over the past 15 years the countries of central and eastern Europe have been discarding the Soviet system of health care. ${ }^{1-5}$ A key element of many of the reforms is the replacement of the old model, based on narrow specialties located in policlinics, with one of integrated primary care, centred on general practitioners (GPs). Despite a formal commitment to primary care, in reality this sector had been starved of resources. It delivered poor quality care and had a low threshold for referral to hospital. ${ }^{6}$

Development of a new model of general practice began in Russia the 1980s, with pilot projects in St Petersburg, Kemerovo, and Samara; in 1992 the Russian Ministry of Health enacted the legislation that provided the basis for reform. ${ }^{89}$ A new training curriculum was developed at the federal level, while allowing regional variations; training centres were established, often with help from international donors. The first cohort of GPs was trained in 1992.

The adoption of a model based on general practice sought to strengthen primary care while tackling excessive specialisation, ${ }^{3}{ }^{10}$ although other factors were also at work. There was a political imperative to converge with western European models, of which that in the United Kingdom was among the best known. Western donors were also influential, arguing that radical change would be easier than reforming the entrenched policlinic model. ${ }^{11}$ However, critics have argued that the transformation of specialists into generalists has been problematic and demotivating, requiring a major investment in training and institutional change. Others have observed how newly trained staff have often become isolated, leading to two often disconnected models of care, with fundamental structural problems being ignored. ${ }^{12}$ This has led some commentators to argue that it would have been preferable to reorganise the policlinics (retraining district physicians and creating incentives for them to retain patients), engage in health promotion, and integrate primary and secondary care. ${ }^{12}$ On the other hand, family practice has been implemented successfully in some places where there has been a coherent reform framework, with institutional support and consistent incentives. ${ }^{13}{ }^{14}$ Which model is best remains a subject of debate, although the general practice model has been universally implemented, with little testing of alternatives.

Despite the scale of the reform taking place, and the large investment involved, little information is available on how the new model is working. We describe here the implementation of general practice in Russia. We explore the views of the directors of all 15 general practice training centres that are currently operational in Russia, acquired through a question-

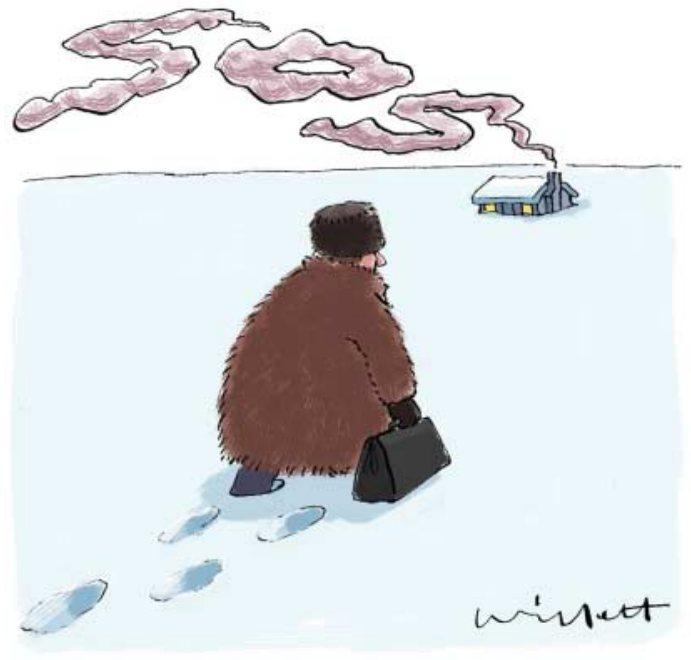

Over a quarter of Russia's population is rural, yet only a minority of the newly trained GPs work in these areas

naire survey in 2002 and through subsequent interviews that explored some issues in more detail.

\section{Where does training take place?}

The settings for training are diverse.$^{15}$ Some are in specialised medical academies-for example, Moscow and St Petersburg-whereas others are in district or regional health departments. In the republic of Chuvashia the training centre is part of the republic's Ministry of Health. The first centres (in Moscow and Khabarovsk) opened in 1992, the latest training centre in 2001 (in Kazan). At the time of the survey, 2413 GPs had already been trained and 516 were being trained. The average annual number of GPs who had been trained varied widely across Russia (from under three in Yaroslavl to 104 in St Petersburg Medical Academy), with an average of 29. Most trainees were women, and most were aged under 40 (table 1). The percentage of newly qualified doctors taking up posts in general practices that had been established under the new reforms varied greatly across Russia (mean 63\%), reflecting regional differences in the pace of reform, leadership, and available international assistance (table 2).

Table 1 Number (percentage of total) of general practitioners in training during 2001-2 in Russia, by age and sex

\begin{tabular}{|c|c|c|c|c|}
\hline \multirow[b]{2}{*}{ Sex } & \multicolumn{3}{|c|}{ Age (years) } & \multirow[b]{2}{*}{ Total No } \\
\hline & $<40$ & $40-49$ & $\geq \mathbf{5 0}$ & \\
\hline Male & $66(12.8)$ & $27(5.2)$ & $8(1.6)$ & 101 (19.6) \\
\hline Female & $223(43.2)$ & $148(28.7)$ & $44(8.5)$ & $415(80.4)$ \\
\hline Total & $289(56.0)$ & 175 & $52(10.1)$ & $516(100)$ \\
\hline
\end{tabular}




\section{Organisation of primary care in Russia}

At city and district level in Russia, primary care is delivered in policlinics, whereas in rural areas it is mostly delivered in small primary care practices (which are staffed by feldshers-a form of paramedic-and nurses)

Russia has three categories of policlinics: for adults; mothers and children; and those with specific disorders (such as tuberculosis, oncology, sexually transmitted diseases, mental disorders, and addictions) Policlinics are staffed by district physicians, each responsible for a geographically defined population of typically 1700 people. In addition, the clinics have "outpatient specialists," most often in internal medicine, paediatrics, obstetrics and gynaecology, and otorhinolaryngology. Less often they have GPs. There are also parallel systems serving the employees of some ministries and industries. The small private sector consists mainly of GPs and outpatient specialists.

Policlinic staff provide only basic treatment and little gatekeeping or follow-up, and these clinics are often bypassed, with patients seeking hospital care through formal or informal channels. Primary care has had a low priority and is poorly funded

\section{Institutional arrangements}

The largest share of new GPs $(75 \%)$ returned to work in traditional district policlinics and in outpatient facilities linked to industries $(5 \%)$. Both types of facilities are mainly in urban areas; only $8 \%$ of new GPs worked in rural facilities, although $27 \%$ of the population is rural. ${ }^{16} \mathrm{~A}$ few $(6 \%)$ went to independent practices or private facilities; for $6 \%$ the destination was unknown. Although about $75 \%$ of trainees were in posts designated as general practice, respondents reported that returning trainees faced major barriers in applying what they had learnt, facing opposition from senior doctors, unreformed financing structures, and scarce equipment. One respondent stated that only one of 117 GPs trained in that region was now working as a GP-in a small rural facility. According to other respondents, however, change was possible.

Directors of all training centres identified the need to improve the vague federal regulatory framework, with formal specification of the scope of general practice. Yet where guidelines (for example, on educational standards) exist, the training content varies between the training centres (table 3).

General practice is financed from compulsory health insurance (12 centres), municipal and regional budgets (10 centres), and, rarely, from the federal budget (three centres). Most GPs were paid salaries, although four regions are experimental sites that have introduced other methods. Respondents showed enthusiasm for a shift to capitation payments. Many commented on the large discrepancy between the average monthly income of GPs in state and private primary care facilities (2091 roubles $(£ 41 ; \$ 73 ; € 61) v$ 13820 roubles).

Before the reforms, concerns had been raised that general practice would be unpopular with patients, who would prefer to consult specialists. Respondents indicated, however, that staff working in posts designated as GP posts, were very popular with patients despite the constraints.

Another expectation was improved quality of care, as GPs would see fewer patients whom they would know better. Responses showed that the daily workload of the new GPs is (with some exceptions) lower than that of the traditional district physician (19 $v 23$ patients a day)-and less than would be expected in western Europe.

\section{Constraining factors}

Virtually all respondents identified conditions in policlinics as extremely difficult for newly trained GPs. Insufficient funds led to a lack of basic equipment (office equipment, supplies, telephones) and transport to conduct home visits with patients.

Equally important, as already noted, is the vague federal legislation and the lack of specific local provisions. The scope of general practice is not clearly defined, leading to boundary disputes with specialists. Those working in policlinics receive no recognition of their extended role and soon revert to the old model of practice, providing superficial cover for large numbers of patients.

Other common problems included lack of support from health administrations and opposition from "narrow" policlinic specialists and hospital physicians, who see their status and professional dominance being undermined. Many reported at best lack of support and at worst hostility from head physicians in policlinics and regional hospitals, few of whom have been exposed to new concepts. Adoption of new roles, including health promotion, working in partnership with social services, and care for elderly or disabled people, often clash with the dominant paradigm. The difficulty in bringing about change is illustrated by the experience of several regions in Siberia, where separate training programmes for "adult" and "paediatric" GPs have been retained because of the perceived threat to the existing paediatric outpatient infrastructure (abstracts of the second all-Russia conference of GPs, St Petersburg, April 2003).

Directors were asked to use a five point scale (1, very bad; 5 , very good) to rate the extent of support for

Table 2 Capacity of training centres in Russia (data not available for Volgograd) up to 2002

\begin{tabular}{lccc} 
& $\begin{array}{c}\text { Total No (annual } \\
\text { average) of GPs } \\
\text { trained }\end{array}$ & $\begin{array}{c}\text { No of years } \\
\text { centre has been } \\
\text { established }\end{array}$ & $\begin{array}{c}\text { \% of GPs trained who } \\
\text { are working as GP }\end{array}$ \\
\hline Samara & $768(85)$ & 9 & 93 \\
\hline $\begin{array}{l}\text { St Petersburg Medical Academy for } \\
\text { Postgraduate Studies }\end{array}$ & $520(104)$ & 5 & 97 \\
\hline Moscow Medical Academy & $320(32)$ & 10 & 75 \\
\hline Perm & $147(18)$ & 8 & 46 \\
\hline Tyumen & $140(20)$ & 7 & 44 \\
\hline Chuvashia & $120(60)$ & 2 & 49 \\
\hline Stavropol & $117(29)$ & 4 & 12 \\
\hline St Petersburg Mechnikov & $60(5)$ & 12 & 27 \\
\hline Arkhangelsk & $56(9)$ & 6 & 77 \\
\hline Khabarovsk & $53(5)$ & 10 & 0 \\
\hline Chelyabinsk & $40(8)$ & 5 & 40 \\
\hline Astrakhan & $29(4)$ & 8 & 83 \\
\hline Kazan & $25(25)$ & 1 & \\
\hline Yaroslavl & $18(3)$ & 7 & \\
\hline
\end{tabular}


Table 3 Training content for general practitioners that is covered in the 15 training centres in Russia

\begin{tabular}{|c|c|c|c|c|c|c|c|}
\hline & $\begin{array}{l}\text { Family } \\
\text { planning }\end{array}$ & Child immunisation & $\begin{array}{c}\text { Developmental } \\
\text { check-ups in children }\end{array}$ & PAP smear & $\begin{array}{l}\text { Minor } \\
\text { surgery }\end{array}$ & Ultrasound & $\begin{array}{l}\text { Care for chronic } \\
\text { diseases }\end{array}$ \\
\hline \multicolumn{8}{|l|}{ Arkhangelsk } \\
\hline \multicolumn{8}{|l|}{ Astrakhan } \\
\hline Chelyabinsk & & $\bullet$ & & $\bullet$ & $\bullet$ & & $\bullet$ \\
\hline Chuvashia & - & - & & & - & & - \\
\hline Kazan & & & & $\bullet$ & $\bullet$ & & $\bullet$ \\
\hline Khabarovsk & $\bullet$ & $\bullet$ & $\bullet$ & $\bullet$ & $\bullet$ & $\bullet$ & $\bullet$ \\
\hline Moscow Medical Academy & $\bullet$ & $\bullet$ & $\bullet$ & $\bullet$ & $\bullet$ & & $\bullet$ \\
\hline Perm & $\bullet$ & $\bullet$ & & $\bullet$ & $\bullet$ & & $\bullet$ \\
\hline Samara & $\bullet$ & & & & $\bullet$ & & $\bullet$ \\
\hline $\begin{array}{l}\text { St Petersburg Medical } \\
\text { Academy for } \\
\text { Postgraduate Studies }\end{array}$ & $\bullet$ & $\bullet$ & & $\bullet$ & & & $\bullet$ \\
\hline St Petersburg Mechnikov & $\bullet$ & & & & & & $\bullet$ \\
\hline Stavropol & $\bullet$ & $\bullet$ & $\bullet$ & $\bullet$ & $\bullet$ & & $\bullet$ \\
\hline Tyumen & $\bullet$ & & $\bullet$ & & - & & - \\
\hline Volgograd & & $\bullet$ & & $\bullet$ & & & $\bullet$ \\
\hline Yaroslavl & & & & & & & - \\
\hline
\end{tabular}

general practice by key stakeholders in the healthcare system. Patients were reported as being the group most positive about GPs; the mean value attributed to patients was 3.8. The mean value attributed to health authorities was 3.3. Hospital and policlinic specialists were considered to be hostile to general practice (2.8 and 2.5 respectively). Chief physicians in regional hospitals were seen as slightly more positive (3).

\section{Discussion}

Implementation of primary care reform in Russia has proved difficult and slow. ${ }^{17}$ The scale of the task has been underestimated, given the estimated need for 90000 GPs in Russia (based on one per 1500 population). Only about 2500 have so far been trained ${ }^{18}$; even when added to the 29789 district physicians, trained under the old system, they will cover only $35 \%$ of the population. ${ }^{17}$ Russia is not, however, unique in failing to understand the scale of the task..$^{23}$

Earlier reform efforts have also been problematic, such as the Leningrad experiment and related activities, ${ }^{19-21}$ in which regional and local governments were briefly given the right to set up contracts with provider associations, subsequently deemed inconsistent with the new compulsory insurance system. ${ }^{22}$

The study findings highlight the importance of a system-wide approach. While some new elements of primary care have been put in place, many others are missing. Many trainees return to work in facilities lacking the infrastructure and procedures needed for new models of care. The broad, federal legislative framework provides no detailed guidance on the roles and responsibilities of general practitioners and their relationship with specialists. GPs have little opportunity to use new skills. Little evidence exists of meaningful integration into the healthcare system, with the persisting hierarchical and hospital dominated system leading to demoralisation. Yet the new model seems popular with patients, as has also been noted in other former communist countries. ${ }^{23} 24$

Change is needed at several levels. Firstly, there is a need for supportive legal and regulatory frameworks to exist at federal level, allowing regional authorities to develop locally applicable policies. An explicit human resource strategy should tackle staff motivation and retention. Incentives must be aligned with the goals of reform and be system-wide, taking account of those working in primary and secondary care.

Secondly, resources are needed to support change. The Russian healthcare system is moving from a model based on cheap, poor quality labour to one with fewer, skilled people supported by modern technology. This is bound to be painful, eliciting opposition from those with most to lose. The process of change will inevitably require targeted investment and technical support.

The directors identified municipalities as important stakeholders, contrary to widely held assumptions about the importance of regional health authorities. Garnering support from local stakeholders who can facilitate change, but who often obstruct it, is essential.

This study suggests serious weaknesses in general practice in Russia, a similar situation to that in some other eastern European countries, ${ }^{25}$ yet many stakeholders support change. The prevailing paradigm will have to change if the reforms are to succeed.

\section{Summary points}

Most central and eastern European countries are replacing the Soviet model of primary care (based on policlinics) with a system of integrated general practice

Little information is available, however, on the progress of these reforms

In Russia, reform has been hampered by an adverse regulatory and working environment, poor professional recognition of general practitioners, inadequate healthcare infrastructure, and weak financing mechanisms

Successful reform will require changes in the legislative and policy framework and better management of staff and resources; institutions' resistance to change will also have to be tackled 
$\mathrm{KD}$ is also a research fellow at the London School of Hygiene and Tropical Medicine, London.

Contributors and sources: All authors contributed to the initial idea, the study design, and data analysis. AR led the data collection in Russia, emailing semistructured questionnaires to directors of general practice training centres in Russia in 2002. DB analysed the data and produced the first and the final drafts, with inputs from KD, AR, and MMcK. MMcK also edited the manuscript. All authors contributed to the analysis and the writing and have approved the final manuscript.

Funding: The authors are members of the Health Systems Development Programme, which is funded by the UK Department for International Development (DFID). The DFID supports policies, programmes and projects to promote international development. DFID provides funds for this study as part of that objective, but the views and opinions expressed are not necessarily those of the DFID.

Competing interests: None declared.

Ethical approval: Not required.

1 Lember M. A policy of introducing a new contract and funding system of general practice in Estonia. Int J Health Plann Manage 2002;17:41-53.

2 Lovkyte L, Padaiga Z. Physician workforce reform in Lithuania: an inevitable transition. Cah Sociol Demogr Med 2001;41:347-68.

3 Reamy J, Gedik G. Health human resource reform in Tajikistan: part of a masterplan for change. Cah Sociol Demogr Med 2001;41:327-45.

4 Kersnik J. Determinants of customer satisfaction with the health care system, with the possibility to choose a personal physician and with a family doctor in a transition country. Health Policy 2001;57:155-64.

5 Earl-Slater A. Health-care reforms in the Czech Republic.J Manag Med 1996:10:13-22.

6 Ryan M, Stephen J. General practitioners and family doctors in the Russian Federation. Br J Gen Pract 1996;46:487-9.

Sheiman I. The development of market approaches in Russia. Healt Policy 1995;32(1-3):167-80.

8 Ministry of Health of Russian Federation. Decree \#237: On stepwise transition of outpatient services to general practice model. Moscow, 1992. www/techno.edu.ru/db/msg/7033.html (accessed 22 Jun 2005).

9 Government of Russian Federation. Basis of legislation on health protection in Russia. Moscow, 1993. www.doktor.ru/econom/law/patient/osn.htm (accessed 22 Jun 2005)
10 Koppel A, Meiesaar K, Valtonen H, Metsa A, Lember M. Evaluation of primary health care reform in Estonia. Soc Sci Med 2003;56:2461-6.

11 World Bank. Health, nutrition and population in Europe and Central Asia.A decade of experience: lessons learned, implications for the future. 2003. http://siteresources.worldbank.org/INTECAREGTOPHEANUT/ Resources/HNPinECA_Dec2003_Ch1.pdf (accessed 22 Jun 2005).

12 Sharbarova Z. Primary health care in the NIS: history and current situation. An overview. American Iinternational Health Alliance, 2001. wwwaiha.com/ resources/Html/zova.htm (accessed 22 Jun 2005).

13 McEuen M. The pilot process: case study on piloting complex health reforms in Kyrgyzstan. Abt Associates, 2004. (www.phrplus.org/Pubs/Tech036_ fin.pdf) (accessed 22 Jun 2005).

14 Abzalova R, Wickham C, Chukmaitov A, Rakhipbekov T. Reform of primary health care in Kazakhstan and the effects on primary health care worker motivation: the case of Zherkargan region. 1998 (major applied research 5 , 2005)

15 Orlova GG, Gadzhieva LSh, Kalininskaia AA. [The training of family physicians.] Ter Arkh 1992;64:114-6. (In Russian.)

16 Goskomstat. Population census of the Russian Federation. Moscow: Goskomstat, 2002. www.perepis2002.ru/index.html?id=11 (accessed 22 Jun 2005).

17 Tishuk EA, Shchepin VO. [Topical issues of the primary medical and sanitary care.] Probl Sotsialnoi Gig Istor Med 2003;2:28-30. (In Russian.)

18 Ministry of Health. Indicators of health and health care. MoH: Moscow, 2003.

19 Chernichovsky D, Potapchik E. Genuine federalism in the Russian health care system: changing roles of government. $J$ Health Polit Policy Law 1999;24:115-44

20 Sheaff R. An international comparison: the Leningrad experiment. In: Cook H, ed. The NHS-private sector interface. Longman: Harlow, 1990: $33-46$.

21 Curtis S, Petukhova N, Taket A. Health care reform in Russia: the example of St Petersburg. Soc Sci Med 1995;40:755-65.

22 Shchepin OP, Tregubov IuG, Rytvinskii SS, Parkhachev VF. [Integration activities of a central municipal hospital.] Probl Sotsialnoi Gig Istor Med 2001; Jan-Feb:11-3. (In Russian.)

23 Polluste K, Kalda R, Lember M. Evaluation of primary health care reform in Estonia from patients' perspective: acceptability and satisfaction. Croat Med J 2004;45:582-7.

24 Kersnik J. An evaluation of patient satisfaction with family practice care in Slovenia. Int J Qual Health Care 2000;12:143-7.

25 Boerma W. Profiles of general practice in Europe. An international study of variation in the tasks of general practitioners. Utrecht: Netherlands Institute for Health Services Research (NIVEL), 2003

\section{Don't give up hope}

In a recent visit to the intensive care unit I saw a 69 year old Hindu patient. His case was unusual in that he had been brought back to our hospital after active treatment had been declined by his family at an earlier presentation.

He had first visited the hospital 25 days previously for limb weakness and bladder and bowel incontinence associated with dizziness but no headache. He had no spinal injury, and the results from magnetic resonance imaging were normal. He was sent back home with conservative management-corticosteroid, multivitamins, and treatment for his concurrent illnesses of benign enlargement of the prostate and hypertension.

The patient then developed acute retention of urine, for which he was taken to another hospital and catheterised. He was admitted for 10 days, and during that time he developed absolute constipation, which was relieved with an enema. He was discharged back home.

At home he developed abdominal pain and distension, constipation, and reduced urine output, and was brought back to our hospital. His general condition was poor, and a provisional diagnosis of peritonitis secondary to bowel perforation was made. This was explained to his family, who were asked for permission to undertake a diagnostic laparotomy. The family, however, refused: they thought that he was approaching death and that he wouldn't benefit from further active treatment. Instead, they wanted to allow him to die at Pashupatinath temple. The doctors therefore simply inserted two abdominal drains under local anaesthetic, and about $50 \mathrm{ml}$ of fluid drained from each.

The patient was duly taken to Pashupatinath to await death in the vicinity of the great Hindu god Pashupati. During their wait, the family members felt that the patient showed some improvement and so brought him back to our hospital. This time they gave the high risk consent for emergency laparotomy. This revealed multiple jejunal diverticula and a large perforation in one of them. After resection and anastomosis, the patient's condition rapidly improved.

Many Hindus believe that dying at a holy site will secure a place in heaven, and strive to achieve this. However, this can create a dilemma as to when to go to the temple or shrine of choice, where there are unlikely to be any treatment facilities. It is very difficult for family members to make such a decision for a patient who is elderly with multiple illnesses. In my opinion, however, the question of when to die should be more important than choosing where to die. We should obviously respect patients' wishes, but it is equally important to teach them that they should give treatment a chance first. "Saas rahe samma aas" [Hope till the last breath] as a motivational Nepali proverb says.

Kaushal Raj Pandey medical student, Institute of Medicine, Kathmandu,Nepal (krpandey702@emailaccount.com) 